\title{
Defending Davidson's Anti-skepticism Argument: A Reply to Otavio Bueno
}

\author{
Mohammad Reza Vaez Shahrestani \\ University of Bonn
}

\begin{abstract}
In the article of Bueno titled "Davidson and Skepticism: How Not to Respond to the Skeptic," he intends to demonstrate that although Davidson's theory of Coherence holds many attractions, it does not entail a response to any kinds of skepticism including Global, Lottery, and Pyrrhonian. In this study, the goal is to criticize the work of Prof. Bueno in connection with two criticisms raised by him over Davidson's anti-skeptical strategy. Further, by giving some reasons in favor of Davidson's anti-skepticism argument, it will be shown that neither the above stated criticisms nor the global skepticism response could undermine the validity of anti-skepticism argument.
\end{abstract}

Keywords: Donald Davidson, Otavio Bueno, global skepticism, transcendental argument

\section{Introduction}

There are different kinds of skepticism and for each kind there is a corresponding argument that the skeptic provides as a challenge to those who claim to have the relevant knowledge about the world. Three kinds of those which differ in their plausibility and in how radical they are include Global, Lottery, and Pyrrhonian. ${ }^{1}$

According to global skepticism, which is the target of our discussion, we don't have knowledge about the world, since all of our beliefs about the world may be false. There are three prevalent arguments presented for global skepticism including Cartesian, Humean, and the brain-in-the-vat hypothesis. In spite of the fact that some philosophers consider these forms of global skepticism deferent from each other, a short overview of each argument will be enough to show why a philosopher such as Donald Davidson did not distinguish among them. ${ }^{2}$ Davidson often referred to three aforementioned forms of global skepticism (Cartesian, Humean, and the brain-in-the-vat hypothesis) equivalently (Peto 2009, 1-2):

For clearly a person's sensory stimulations could be just as they are and yet the world outside very different. (Remember the brain in the vat.) (Davidson 1983, 430)

But it does seem to me that if you accept perceptual externalism, there is an easy argument against global skepticism of the senses of the sort that Descartes, Hume, Russell, and endless others have thought requires an answer. (Davidson 1990a, 200)

For the Cartesian or Humean skeptic about the external world holds that it is all too obvious that we can get along without knowledge of the world of nature-what we know of our own mind is self-sufficient, and may be all the knowledge we have. (Davidson 1991, 208)

Mohammad Reza Vaez Shahrestani, Ph.D. Researcher, Institute of Philosophy, Rheinische Friedrich-Wilhelms-Universität Bonn (University of Bonn), Germany; main research field: Epistemology, Philosophy of Mind and Philosophy of Language. 
He introduces a coherence theory of truth and knowledge, proposing a new form of externalism and using his theory of radical interpretation, and tries to address a problem raised by some kind of skepticism. Initially, it is clarified what Davidson means by skepticism. This initial step is important why we can grasp whom Davidson was going to respond to (or at least whom he thought he was responding to).

The beginnings of a clear understanding of what Davidson considered as skepticism can be found in "A Coherence Theory of Truth and Knowledge," where Davidson wrote:

This is skepticism in one of its traditional garbs. It asks: why couldn't all my beliefs hang together and yet be comprehensively false about the actual world? Mere recognition of the fact that it is absurd or worse to try to confront our beliefs, one by one, or as a whole, with what they are about does not answer the question nor show the question unintelligible. (Davidson 1983, 140)

In the above quote, referring to all "our beliefs," Davidson want to say that there is a possibility that all of our beliefs about the world would be false and it means that we don't have knowledge about the world and it is the same definition of global skepticism.

In addition, the problem of global skepticism in "Epistemology Externalized" is presented although here also Davidson did not specifically use the term of "global skepticism." He wrote: "Yet it has seemed obvious to many philosophers that if each of our beliefs about the world, taken alone, may be false, there is no reason all such beliefs might not be false" (Davidson 1990, 194). Again this is the same conclusion like above quote, i.e., as there is a possibility that all of our beliefs would be false, we don't have knowledge about the world (Peto $2009,6)$.

On the other hand, in his article titled "Davidson and Skepticism: How Not to Respond to the Skeptic," Prof. Otavio Bueno aims to show that although Davidson's theory of coherence holds many attractions, it does not involve a response to no kinds of skepticism including Global, Lottery, and Pyrrhonian. As mentioned above, referring to Davidson's text concerning epistemology and language, we can find that he was not going to solve all kinds of skepticism but he only aimed at the issue discussed by global skeptics, who claim that it is not possible to have knowledge about the world. Thus, it is unnecessary to search for an argument that encompasses a response to two other kinds of skepticism in Davidson's text.

In this article, I will criticize the work of Bueno relating to two criticisms raised by him over Davidson's anti-skeptical strategy. Finally, the global skepticism response to Davidson's anti-skepticism strategy explained in section 4-2 of Bueno's article will be investigated and further will be concluded that even having an mental state like skepticism, we need also to assume most of beliefs are true and if this is not the case, mankind suffers from an absolute skepticism where the existence of any mental state including skepticism about the knowledge of the world will be impossible.

\section{Resisting Bueno's Criticisms}

\subsection{Resisting Bueno’s First Criticism}

As mentioned above, in section 4-1 of his article, Prof. Bueno tries to invalidate the anti-skepticism argument developed by Davidson by making two criticisms against it. By presupposing Davidson's commitment to classical first-order modal logic, the first criticism targets at incoherence between two statements presented by Davidson. These statements are as follows:

(i) Each belief can be false (Davidson 1983, 140). 
(ii) It is not the case that all beliefs can be false (Davidson 1983, 140).

Bueno suggests that by adopting classical first-order modal logic, the first statement can be expressed as follows:

(i) $\diamond \neg \mathrm{T}(\mathrm{Pa}) \wedge \diamond \neg \mathrm{T}(\mathrm{Pb}) \wedge \ldots \wedge \diamond \neg \mathrm{T}(\mathrm{Pn})($ Bueno 2005, 11).

He also formulates the second statement as follows:

(ii) $\neg \diamond \forall \mathrm{x} \neg \mathrm{T}$ (Px) (Bueno 2005, 11).

As a result, since Bueno believes that the negation of (ii) follows from (i) in the classical first-order modal logic, he knows it as an incoherent view in Davidson's argument and therefore considers the argument as an invalid argument (Bueno 2005, 11).

From the author's point of view, the first criticism raised by Bueno over Davidson's argument has two problems: The first problem of the first criticism made by Bueno refers to his argument's structure; since he formulates his argument so as Davidson is going to inference from the statement "each belief can be false" to an anti-skepticism conclusion, i.e., "it is not the case that all beliefs can be false." Davidson wrote: "I think the independence of belief and truth requires only that each of our beliefs may be false. But of course, a coherence theory cannot allow that all of them can be wrong" (Davidson 1983, 140). He also wrote: "Of course some beliefs are false... All that a coherence theory can maintain is that most of the beliefs in a coherent total set of beliefs are true" (Davidson 1983, 138). As a matter of fact, offering some reasons, Davidson firstly supposed that most of our beliefs are true and then he mentioned that it is not also the case that all of our beliefs are true and definitely, some of them are false. It means that the trend of Bueno's argument is exactly contrary to Davidson's philosophical work. Meanwhile, if one asks about Davidson's reasons for the aforementioned presupposition, he/she can find the answer at the end of this article.

Second, the translation of statement (i) in the above logical formulation is not correct, because the predicates ought to be logically independent of each other in the classical logic, as Bueno himself admits rejecting the counter-example for his argument in his article. ${ }^{3}$ Bueno wrote: "However, a crucial assumption of classical first-order logic is that all predicates are logically independent of eachother" (Bueno 2005, 11). Therefore, once Davidson says that each belief can be false, even in this statement, the falsity of each belief is dependent on the truth value of other beliefs. In other words, Davidson is of the conviction that a belief can be false once most of the other beliefs are true. Indeed, he considers the falsity possibility of each belief having presupposed that most of the other beliefs are true previously. Consequently, the statement "Each belief can be false" is similar to the counter example mentioned by Bueno and one cannot formulate it like (i) based on the classical first-order modal logic and conclude that the negation of (ii) follows from it.

\subsection{Resisting Bueno's Second Criticism}

In this section, I will review the latter criticism raised by Bueno over the Davidson's anti-skepticism strategy. In this regard, Bueno suggests that the consistency of one belief with a coherent body of beliefs is not sufficient for that belief to be true. He emphasizes that Davidson himself does not reject such a claim. He says:

The coherentist may complain that it's indeed true that we cannot guarantee that each particular belief is true. But those beliefs that cohere (i.e. are consistent) with a body of beliefs are true or, at least, are likely to be so. Even here, however, there is trouble. After all, consistency with a body of beliefs is not sufficient for truth, as Davidson wouldn't deny. (Bueno 2005, 12) 
As Bueno said Davidson himself admits this point. He in this regard wrote: "So mere coherence, no matter how strongly coherence is plausibly defined, cannot guarantee that what is believed is so" (Davidson 1983, 138). However, Davidson's presupposition (i.e., most beliefs are true) has been disregarded here. Davidson in the following said: "All that a coherence theory can maintain is that most of the beliefs in a coherent total set of beliefs are true" (Davidson 1983, 138). In fact, Davidson believes that once a belief is consistent with a coherent body of beliefs which are mostly true, that belief will be true as well. He wrote: "Perhaps it is obvious that the coherence of a belief with a substantial body of belief enhances its chance of being true, provided there is reason to suppose the body of belief is true, or largely so" (Davidson 1983, 140).

Therefore, with respect to the fact that Davidson believes that a belief is true when it coheres with a coherent body of beliefs which are mostly true, the sufficient condition for truth will be also satisfied and so the second criticism of Bueno will not be raised.

\section{Resisting the Global Skepticism Response}

Global skepticism asks whether our beliefs about the world can all be true and as Bueno says "it looks as though Davidson's target in his refutation of skepticism is this kind of skepticism" (Bueno 2005, 13).

The global skepticism response to Davidson's anti-skepticism strategy is explained in section 4-2 of Bueno's article where he says:

Faced with the brain-in-a-vat argument, Davidson presumably would deny the coherence of the skeptic's scenario. It's simply not possible to entertain the possibility of a massive mistake in our beliefs, given that the latter are mostly veridical. In response, the global skeptic would insist that whether such beliefs are veridical or not is precisely the issue that the brain-in-a-vat argument raises. Thus, to presuppose that beliefs are mostly true is to assume the point in question, and the move fails as a response to global skepticism. (Bueno 2005, 13)

Then Bueno mentioned that Davidson could answer quickly that he has not presupposed our beliefs are veridical. Rather, this claim is the result of an argument to the effect that the conditions of possibility of communication require that the speaker's beliefs be mostly true (Bueno 2005, 13). For this purpose, with regard to Davidson never explicitly schematized his own argument, I will try to reconstruct Davidson's anti-skepticism argument on his behalf in a few premises. The argument goes as follows:

(1) I have a belief (P).

(2) If true beliefs can be justified, then the necessary and sufficient conditions for knowledge about the world have been satisfied. ${ }^{4}$

(3) Due to the holistic nature of belief, having one belief involves having many beliefs. ${ }^{5}$

(4) Having many beliefs involves that there is a language. ${ }^{6}$

(5) Having language involves the ability of the interpretation of language. ${ }^{7}$

(6) In order for the interpretation of language to occur, three necessary conditions must be satisfied: ${ }^{8}$

a. There must be a shared public world.

b. A speaker's beliefs must be mostly true.

c. An interpreter's beliefs must be mostly true.

(7) From (6), if the interpretation of language occurs, language users will have mostly true beliefs about the world.

(8) The interpretation of language occurs (or language users are interpretable).

(9) From (7) and (8), language users will have mostly true beliefs about the world. 
(10) From (9), true beliefs are justified.

(11) Therefore, from (2) and (9), the necessary and sufficient conditions for knowledge about the world have been satisfied.

In this case, also Bueno believes that Davidson's method fails and the skeptic would be unaffected.

He wrote:

Davidson's argument about the functioning of language and the way in which communication among speakers emerges does presuppose that beliefs are true. In fact, his examination of radical interpretation- roughly, the process that allows us to interpreter meaning discourse, whether foreign or domestic- can only get off the ground if the interpreter makes belief attributions to speakers as being mostly true. The method is, of course, perfectly reasonable. But if it is used a response to skepticism, the method ends up assuming the point in question, since it takes most beliefs to be true. (Bueno 2005, 13-14)

With regard to the above, criticism can say even having a skeptical belief something like "I don't have knowledge about the world" or in other words "all of our beliefs about the world may be false," on the basis of Davidson's argument, which needs also to assume most of beliefs are true. It means the argument goes as follows:

(1) I have the belief "I don't have knowledge about the world" or in other words "all of our beliefs about the world may be false."

(2) If true beliefs can be justified, then the necessary and sufficient conditions for knowledge about the world have been satisfied.

(3) Due to the holistic nature of belief, having one belief involves having many beliefs.

(4) On the basis of Davidson's view, having many beliefs involves that there is a language.

(5) Having language involves the ability of the interpretation of language.

(6) In order for the interpretation of language to occur, three necessary conditions must be satisfied:

a. There must be a shared public world.

b. A speaker's beliefs must be mostly true.

c. An interpreter's beliefs must be mostly true.

(7) From (6), if the interpretation of language occurs, language users will have mostly true beliefs about the world.

(8) The interpretation of language occurs (or language users are interpretable).

(9) From (7) and (8), language users will have mostly true beliefs about the world.

(10) From (9), true beliefs are justified.

(11) Therefore, from (2) and (9), the necessary and sufficient conditions for knowledge about the world have been satisfied.

(12) It is not the case that "I don't have knowledge about the world" or "all of our beliefs about the world may be false."

Otherwise, if the skeptic claims that there are no beliefs even a skeptical belief, mankind suffers from an absolute skepticism where the existence of any belief including skepticism about the knowledge of the world will be impossible. 


\section{Notes}

1. Otavi Bueno reviews these kinds of skepticism in turn. Bueno 2005, 3-7.

2. A classic explanation of this claim is the first chapter of Jonathan Peto's Thesis. A Defense of Donald Davidson's Dissolution to the Problem of Global Skepticis. University of California, UMI: Dissertation Publishing, 2009.

3. The counter example as follows: "In a conference, it is possible that each speaker speaks longer than the average time of the speakers. But, clearly, it is not possible that every speaker speaks longer than the average time of the speakers." Bueno 2005, 11.

4. The first premise in this argument, premise (1), defines what Davidson indicated were the conditions of knowledge about the world. Davidson was of the conviction that if we had justification for our true beliefs, we could have knowledge about the world. He sympathized with the coherentists who believe that "nothing can count as reason for holding belief except another belief" (Davidson 1983, 141). In other words, he was in agreement with Rorty who said: "nothing counts as justification unless by reference to what we already accept, and there is no way to get outside our beliefs and our language so as to find some test other than coherence" (Rorty 1979, 178). As a matter of fact, Davidson thought if we look for evidence to justify our beliefs, it will inflame the confrontation. As a result, since the sensations are not like beliefs or other propositional attitudes and we cannot get outside our beliefs, this relation will not be justifying; rather this is only causal. He wrote: "Sensations cause some beliefs and in this sense are the bases or ground of those beliefs. But a causal explanation of a belief does not show how or why the belief is justified" (Davidson 1983, 143). Therefore, on the basis of Davidson's view, if there is a justification for our beliefs to be mostly true, it will be another belief.

5. The justification for premise (3) comes from the holistic account of belief that Davidson took. Davidson is of the conviction that a belief is determined by a system of beliefs; in other words, having a belief requires having a background of beliefs. In fact, beliefs do not occur in isolation, rather they are interdependent. For instance, in order to have the belief that "I will go to a certain concert," I need a system of beliefs in my mind so to have this belief. These beliefs include "I will be put to a degree of trouble and expense," "I will be enjoying my favorite music by attending this concert," etc. Therefore, in order to have this belief, I need to have a background of beliefs that determine this belief for me. Davidson 1975, 157.

6. Vaez Shahrestani 2012, 457, Davidson 1991, 210, and Peto 2009, 17.

7. Vaez Shahrestani 2012, 459.

8. Peto 2009, 22-23.

\section{Works Cited}

Bueno, O. "Davidson and Skepticism: How Not to Respond to the Skeptic." Principia 9.1-2 (2005): 1-18. Brazil: NEL-Epistemology and Logic Research Group. Federal University of Santa Catarina (UFSC).

Davidson, D. Subjective, Intersubjective, Objective. Oxford: Clarendon Press, 2001a.

---. Inquiries into Truth and Interpretation (2nd ed.). Oxford: Clarendon Press, 2001b.

---. "A Coherence Theory of Truth and Knowledge." Kant oder Hegel. Ed. Dieter Henrich. Stuttgart: Keltt-Cotta (Reprinted in Davidson, 2001a, 137-53), 1983. 423-83.

---. "Epistemology Externalized.” Reprinted in Davidson (2001a). 1990. 193-204.

---. "Thought and Talk." Reprinted in Davidson (2001b). 1975. 155-70.

---. "Three Varieties of Knowledge." Reprinted in Davidson (2001a). 1991. 205-20.

Peto, J. A Defense of Donald Davidson's Dissolution to the Problem of Global Skepticism. A Thesis Presented to the Department of Philosophy, California State University, Long Beach. UMI: Dissertation Publishing, 2009.

Rorty, R. "Transcendental Arguments, Self-reference, and Pragmatism.” Eds. R. H. P. Bieri, R. P. Horstmann and L. Krueger. Transcendental Arguments and Science. Dordrecht, Holland: D. Reidel, 1979. 77-103.

Vaez Shahrestani, M. "Davidson's No-Priority Thesis in Defending the Turing Test.” Procedia-Social and Behavioral Sciences 32 (2012): 456-61. 